\title{
Analysis of hoop stress variation of shield tunnel based on Hurst index
}

\author{
Chang Lian-yuan ${ }^{1, a^{*}}$, Liu Dai-guo ${ }^{2, b}$ and Li Xu ${ }^{1, c}$ \\ ${ }^{1}$ College of Geology and Environment, Xian University of Science and Technology, Xian , China \\ ${ }^{2}$ Faculty of Engineering, China University of Geosciences, Wuhan, China

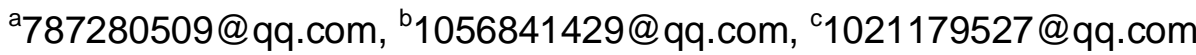

Keywords: Fractal Theory; R/S analysis; V/S analysis; Hurst index; Time series

Abstract.Considering the nonlinearity and uncertainty of first tunnel hoop stress changes that caused by the construction of underwent tunnel in Suzhou metro line 4. According to the basic principles of fractal theory, Hurst index of the hoop stress time series was calculated by using R/S and V/S analysis method. The effectiveness of both method and non-cycle of surface deformation are analyzed combined with V statistic. The results show that both R/S and V/S analysis method for the analysis of time series of hoop stress has good validity. The Hurst index gets from $\mathrm{R} / \mathrm{S}$ analysis method is bigger than that of V/S analysis method. Hurst index of B section in hoop stress time series approaches to one, which suggest that change rule with a strong regularity. The time series of non-cycle of three monitoring points is about 37 days and the hoop stress will be in a stable state after 37 days.

\section{Introduction}

Underwent tunnel shield construction will cause first tunnel segment hoop stress changes, The hoop stress monitoring and analysis its development evolution has guiding significance for normal construction of shield. However, due to the complexity of the construction factors, leading to the hoop stress timing curve showing fluctuations with strong nonlinear characteristics, unable to determine the change trend correctly. Evaluate the stability of hoop stress time sequence curve prediction is particularly important. Currently, there are many kinds of analytical methods for monitoring data to predict its trend of development and evolution. Xiaoguang Jin[1] considered the unpredictability fuzzy factor and predict tunnel deformation using gray model. Shan Zhong[2] introduced the wavelet transform theory into monitoring data processing, studied the shield tunnel construction monitoring project and security early warning. Zhichao Qiao[3] analyzed tunnel surrounding rock deformation using regression models. MengXi Zhang[4] established arch tunnel rock stress and strain forecast model combined with neural network.

However, grey model established on the basis of smooth discrete function, in the case of more data will have a greater deviation. Wavelet analysis method is less to use for predictive analysis and difficult to achieve. Regression analysis is difficult to determine the appropriate regression model, causing evaluation standard is one-sided. BP neural network prediction accuracy analysis is largely dependent on network structure with the characteristic of slow convergence. So the algorithm stability needs to be improved. Measured hoop stress data have the characteristic of respectively, discontinuity, time correlation, etc. The fractal analysis method provides a effective way for its analysis and prediction.

$\mathrm{R} / \mathrm{S}$ and V/S time series analysis methods[5-7] based on fractal theory[8] in the analysis of nonlinear time series of long-range correlation is very effective. Fractal theory is founded by the French mathematician Mandelbrot[9], which is used to describe a class of chaotic, complex and 
have some regular system of self-similarity. Mandelbrot considered that accord with the sequence of Brownian motion is fractal time series, long-term memory as a significant feature, with self-similarity. The study shown that hoop stress time series with self-similarity of fractal characteristics on the statistical. In this paper, combined fractal analysis and nonlinear parameters Hurst index, the hoop stress change rule was analyzed and the application of Hurst index in the stability prediction of hoop stress.

\section{Fractal analysis and Hurst index}

\section{$\mathrm{R} / \mathrm{S}$ and V/S analysis methods}

$\mathrm{R} / \mathrm{S}$ analysis is also called rescaled range analysis, Proposed by Hurst[5] in the study of the law of water level fluctuation of Nile reservoir. Then Mandelbrot developed it into fractal theory. For a sample of time series $\left\{\mathrm{x}_{1}, \mathrm{x}_{2} \cdots \mathrm{x}_{\mathrm{N}}\right\}$ of length $\mathrm{N}$, selected sub-sequence $\left\{x_{1}, x_{2} \cdots x_{n}\right\}$ which time interval is $\mathrm{n}$. Then the sample mean is:

$$
\bar{x}=\frac{1}{n} \sum_{t=1}^{n} x_{t}
$$

Sample variance is:

$$
s_{n}=\left[\frac{1}{n} \sum_{t=1}^{n}\left(x_{\mathrm{t}}-\overline{x_{n}}\right)^{2}\right]^{\frac{1}{2}}
$$

Defined by the Hurst, R/S statistic and V statistic for

$$
\begin{gathered}
(\mathrm{R} / \mathrm{S})_{n}=\frac{1}{s_{n}}\left[\max _{1 \leq k \leq n} \sum_{t=1}^{k}\left(x_{t}-\overline{x_{n}}\right)-\min _{1 \leq k \leq n} \sum_{t=1}^{k}\left(x_{t}-\overline{x_{n}}\right)\right] \\
\mathrm{V}_{\mathrm{n}}=(\mathrm{R} / \mathrm{s})_{n} / \sqrt{n}
\end{gathered}
$$

Cajueiro[6] replaced rescaled range $\mathrm{R} / \mathrm{S}$ with rescaled variance $\mathrm{V} / \mathrm{S}$, and defined $\mathrm{R} / \mathrm{S}$ statistic and $\mathrm{V}$ statistic as follows.

$$
\begin{gathered}
(\mathrm{V} / \mathrm{S})_{n}=\frac{1}{n s_{n}^{2}}\left[\sum_{k=1}^{n}\left(\sum_{t=1}^{k}\left(x_{t}-\overline{x_{n}}\right)\right)^{2}-\frac{1}{n}\left(\sum_{k=1}^{n} \sum_{t=1}^{k}\left(x_{t}-\overline{x_{n}}\right)\right)^{2}\right] \\
\mathrm{V}_{n}^{\prime}=(\mathrm{V} / \mathrm{S})_{n} / n
\end{gathered}
$$

Using R/S and V/S analysis to estimate Hurst index of time series sample and thus test its fractal characteristics, V statistic could verify the stability of fractal analysis and judge non-cycle time series. Corresponding plot $\log (\mathrm{n})$ and $\mathrm{V}$ statistic in the coordinate diagram and obtained V statistic figure. The turning point in the curve that from the rising trend to decline or to steady trend is the non-cyclical cycle of time series.

\section{Hurst index}

$\mathrm{R} / \mathrm{S}$ statistic and V/S statistic have the following relationship with the Hurst index.

$$
\begin{gathered}
(\mathrm{R} / \mathrm{S})_{n}=K n^{H} \\
(\mathrm{~V} / \mathrm{S})_{n} \propto K n^{2 H}
\end{gathered}
$$


Where $K, K^{\prime}$ are the fitting parameters, $H$ is the Hurst index. The time series can be divided into sub-sequences of different group without overlapping. Calculate R/S statistic and V/S statistic of each group. Then take the average of each group which can be write in $(\mathrm{R} / \mathrm{S}) \mathrm{n}$ and $(\mathrm{V} / \mathrm{S}) \mathrm{n}$. With $\log (\mathrm{n})$ as the independent variable, $\log (\mathrm{R} / \mathrm{S}) \mathrm{n}$ and $\log (\mathrm{V} / \mathrm{S}) \mathrm{n}$ as the dependent variable to make a scatterplot. Fitting a straight line using the least squares method, the Hurst index $\mathrm{H}$ could be obtained based on slope of the line.

Hurst index ranges from zero to one [10-13]. When $0<\mathrm{H}<0.5$, time series are anti continuous time series with characteristics of frequent reverse trend and discontinuous tendentious. When $\mathrm{H}=$ 0.5 , the time series are independent, random time series. When $0.5<\mathrm{H}<1$, the time series is continuous time series, with characteristics of continuing trend and cycle sexuality. When $\mathrm{H}=1$, the time series are identified positively correlated systems.

\section{Hoop stress monitoring situation}

The no. 4 rail transit line of Suzhou overall assumes the north-south, springs range between Chun Shenhu road station and Yang Chenghu road station layout mileage right CK4+188.763 right $\mathrm{CK} 5+447.142$, which is bi-directional tunnel and its total length is $1258.379 \mathrm{~m}$. Tunnel center distance is about $10.00 \sim 15.50 \mathrm{~m}$, by using two sets of earth pressure balanced shield machine to move forward, to reduce the shield construction process of soil disturbance, right hole is as early as 2 months compared to the left hole in the construction process. To study the influence of the stress in the segment of the first hole (right hole) after the later hole (left hole) construction process, the strain gage in the segment of the right hole which near the left hole was installed and monitored. Figure 1 and figure 2 shows the strain gauge monitoring and layout, which are respectively in the horizontal position, $+45^{\circ}$ and $-45^{\circ}$ position to install strain gauge. Taking the monitoring section of $\mathrm{CK} 5+080$ as the research object, the monitoring results are shown in figure 3.

Hoop stress time sequence curve can be roughly divided into A, B, C three sections, namely 0 $\sim 20$ days before the adoption of the shield, $20 \sim 40$ days to shield and $40 \sim 60$ days for the shield through, including when the cumulative monitoring time for 30 days, the later hole face arrived in monitoring section. Hoop stress temporal curves show the different changing laws in different stage, before the arrival of the shield (section $\mathrm{A}$ ) and hoop stress along different directions showed the increasing trend, including the level of A trend of compression, $+45^{\circ}$ and $45^{\circ}$ showed a trend of tension, with the arrival of the shield (section B), the changing rule of the tangential stress present strong, monitoring the tension trend on the whole, when the shield arrived the last part (section C), the monitoring gradually stabilized. Overall, the hoop stress an irregular fluctuations temporal curve shape, which is a combination of stochastic system and law system, and has stronger fractal characteristic. 

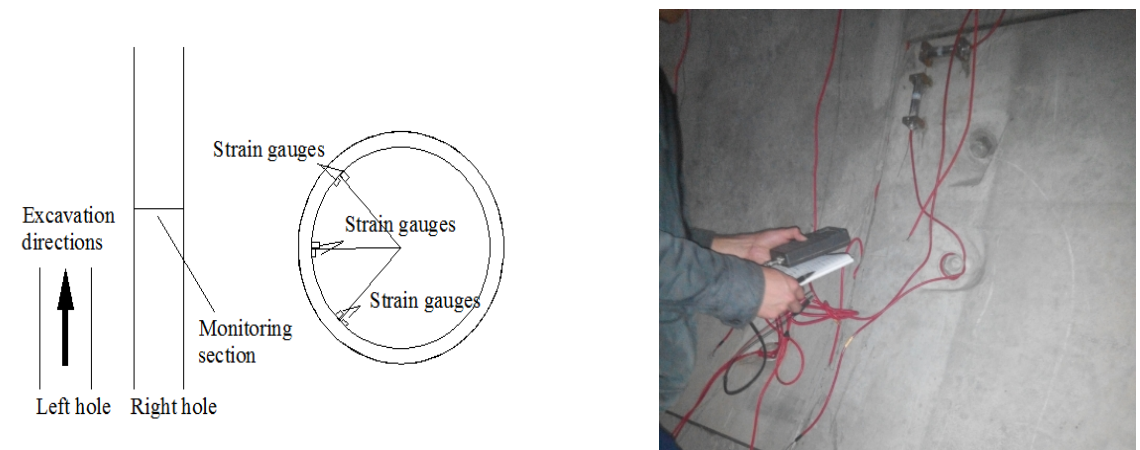

Fig.1 Monitoring points layout

Fig.2 Hoop stress monitoring

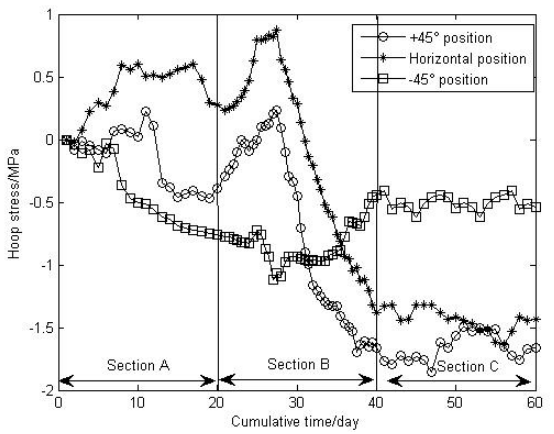

Fig.3 Hoop stress time series

\section{Fractal analysis}

\section{Temporal Hindex}

When the part B of the shield getting through, two times or several times a day is required to monitor, and at other times monitored once a day, so the interpolation or eliminating of the data is required before calculating to make the ring formed stress temporal curve to be the equal time interval curve. According to the basic principle of $\mathrm{R} / \mathrm{S}$ analysis and $\mathrm{V} / \mathrm{S}$ analysis method, the $\mathrm{A}, \mathrm{B}$, $\mathrm{C}$ three parts should be separately dealt with, calculate and draw double logarithmic curves corresponding to each part of the $\mathrm{H}$ index, which obtained by least square method (Table 1). Select the horizontal position at monitoring points as the research object, get the curve segments and the $\mathrm{R} / \mathrm{S}$ and $\mathrm{V} / \mathrm{S}$ analysis results(Figure 4), figure 5 is the horizontal position at monitoring points of $\mathrm{H}$ index in the relationship between the changes of different parts.

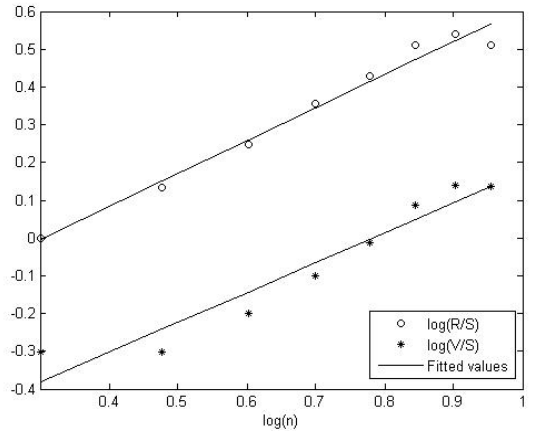

(a) Section A

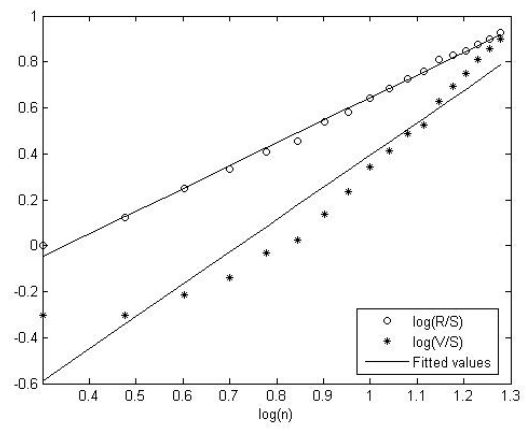

(b) Section B 


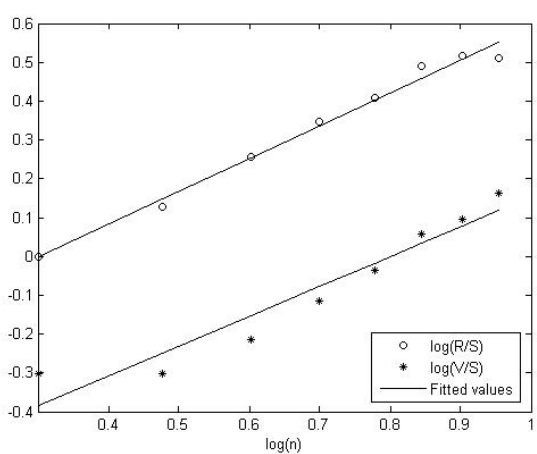

(c) Section $\mathrm{C}$

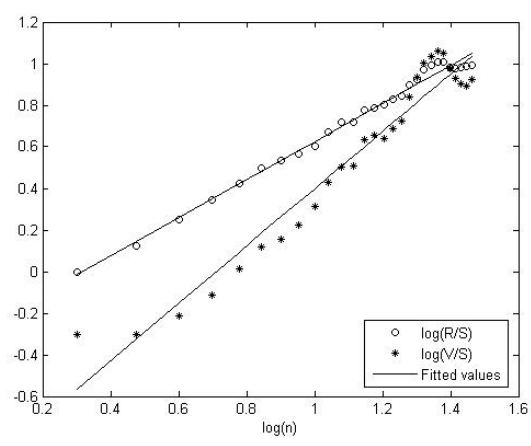

(d)The overall

Fig.4 R/S and V/S analysis of hoop stress time series of horizontal position

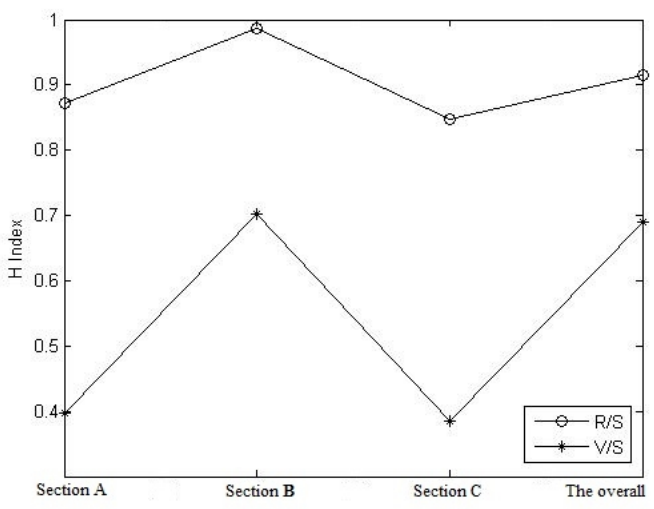

Fig.5 Hurst index of horizontal position

Table 1: The results of fractal analysis

(a) $+45^{\circ}$ postion

\begin{tabular}{|c|c|c|c|c|c|}
\hline \multicolumn{2}{|c|}{ Analytical methods } & Section A & Section B & Section C & The overall \\
\hline \multirow{3}{*}{$\mathrm{R} / \mathrm{S}$} & Fitting function & $y=0.9226 x-0.3146$ & $y=0.9352 x-0.3102$ & $y=0.8167 x-0.2611$ & $y=0.9762 x-0.3471$ \\
\hline & H Index & 0.9226 & 0.9352 & 0.8167 & 0.9762 \\
\hline & $\mathrm{R}$ & 0.9848 & 0.9988 & 0.9933 & 0.9963 \\
\hline \multirow{4}{*}{$\mathrm{V} / \mathrm{S}$} & Fitting function & $y=0.8035 x-0.6654$ & $y=1.2824 x-0.9255$ & $y=0.6613 x-0.5862$ & $y=1.5125 x-1.1134$ \\
\hline & H Index & 0.4018 & 0.6412 & 0.3307 & 0.7563 \\
\hline & $\mathrm{R}$ & 0.8515 & 0.9729 & 0.9076 & 0.9755 \\
\hline & & \multicolumn{4}{|c|}{ (b) Horizontal position } \\
\hline \multicolumn{2}{|c|}{ Analytical methods } & Section A & Section B & Section $\mathrm{C}$ & The overall \\
\hline \multirow{3}{*}{$\mathrm{R} / \mathrm{S}$} & Fitting function & $y=0.8724 x-0.2656$ & $y=0.9873 x-0.3436$ & $y=0.8465 x-0.256$ & $y=0.9146 x-0.2894$ \\
\hline & H Index & 0.8724 & 0.9873 & 0.8465 & 0.9146 \\
\hline & $\mathrm{R}$ & 0.9899 & 0.9980 & 0.9935 & 0.9951 \\
\hline \multirow{3}{*}{$\mathrm{V} / \mathrm{S}$} & Fitting function & $y=0.7928 x-0.6202$ & $y=1.4044 x-1.0101$ & $y=0.7711 x-0.6172$ & $y=1.3777 x-0.9793$ \\
\hline & H Index & 0.3964 & 0.7022 & 0.3856 & 0.6889 \\
\hline & $\mathrm{R}$ & 0.9626 & 0.9637 & 0.9604 & 0.9724 \\
\hline
\end{tabular}


(c) $-45^{\circ}$ position

\begin{tabular}{cccccc}
\hline \multicolumn{2}{c}{ Analytical methods } & Section A & Section B & Section C & The overall \\
\hline \multirow{3}{*}{ R/S } & Fitting function & $\mathrm{y}=0.8233 \mathrm{x}-0.2512$ & $\mathrm{y}=0.9449 \mathrm{x}-0.3353$ & $\mathrm{y}=0.8480 \mathrm{x}-0.2708$ & $\mathrm{y}=0.9952 \mathrm{x}-0.3879$ \\
& H Index & 0.8233 & 0.9449 & 0.8480 & 0.9952 \\
& $\mathrm{R}$ & 0.9954 & 0.9889 & 0.9940 & 0.9939 \\
& Fitting function & $\mathrm{y}=0.6802 \mathrm{x}-0.5790$ & $\mathrm{y}=1.4149 \mathrm{x}-1.0993$ & $\mathrm{y}=0.8385 \mathrm{x}-0.6710$ & $\mathrm{y}=1.6678 \mathrm{x}-1.33$ \\
$\mathrm{~V} / \mathrm{S}$ & H Index & 0.3401 & 0.7075 & 0.4193 & 0.8339 \\
& $\mathrm{R}$ & 0.9450 & 0.9560 & 0.9200 & 0.9774 \\
\hline
\end{tabular}

The analysis results show that the time series of $\log (\mathrm{R} / \mathrm{S})-\log (\mathrm{n})$ and $\log (\mathrm{V} / \mathrm{S})-\log (\mathrm{n})$ graphs has good linear characteristics, using the method of least squares fitting effect is better, the fitting degree of the $\mathrm{R}$ maximum value is 0.998 , the minimum value is 0.8515 , which shows that the calculating $\mathrm{H}$ index reliability is good, each monitoring point of circumferential stress time curves show good fractal character.

On the whole, the $\mathrm{H}$ index obtained by the $\mathrm{R} / \mathrm{S}$ analysis is greater than the results obtained by the $\mathrm{V} / \mathrm{S}$ analysis method, the hoop stress curve is divided into different parts, each part showed different fractal characteristics, while the $\mathrm{H}$ index of section $\mathrm{B}$ is larger than the $\mathrm{H}$ index of remaining two parts. The $\mathrm{H}$ index of three monitoring points in section $\mathrm{B}$ obtained by $\mathrm{R} / \mathrm{S}$ and $\mathrm{V} / \mathrm{S}$ analysis method are both greater than 0.5 , showing that when the shield getting through, it has a significant influence to the hoop stress of monitoring section, whose influence extent is greater than the external uncertain factors, the hoop stress time series curve is continuous and cyclical unity with a strong regularity and the change rule of hoop stress will remain the same as it used to be, showing a strong linear trend. From the measured hoop stress time series curve we can see that the regularity of section B is very strong, during the period of the shield getting through the hoop stress of each monitoring point is basically along the negative direction and continues to increase.

However, in section $\mathrm{A}$ and $\mathrm{C}$ of each monitoring point, the $\mathrm{H}$ index calculated by $\mathrm{R} / \mathrm{S}$ analysis method is greater than 0.5 and the $\mathrm{H}$ index calculated by the $\mathrm{V} / \mathrm{S}$ analysis method is less than 0.5. According to the $\mathrm{H}$ index from 0.5 levels, to determine regularity and randomness of hoop stress changes, when $\mathrm{H}$ index is greater than 0.5 , the identify factors that affect hoop stress accounted for the major part, variation curve of stress showed positive correlation with its original trend, has the same variation. When the $\mathrm{H}$ index is less than 0.5 , the effect of hoop stress of uncertain factors accounted for the main part, the variation is random, the trend was negatively correlated with the original, the more it is less than 0.5 degree, the greater probability of random walk, hoop stress will show a change in the status of irregular. Considering the $\mathrm{H}$ index of the two sections, the uncertain factors are bigger than section $\mathrm{B}$, the fluctuation to the stress change of frequency is larger.

The $\mathrm{H}$ index of hoop stress time series curve of each monitoring point on the overall is greater than $0.5, \mathrm{R} / \mathrm{S}$ analysis and $\mathrm{V} / \mathrm{S}$ analysis are in good agreement, which indicates that these two kinds of analysis methods are more effectively in the case of more data points, and in the situation of less data points the methods are less effectively and will be affected by short-term effect. The $H$ index of each monitoring point is greater than 0.5 , the hoop stress affected by uncertainty factors decreased, consistent with the original,the hoop stress will remain stable.The $\mathrm{H}$ index of -45 degrees position is most close to one, indicating that the regularity of hoop stress at this point is the 
strongest.By the measured data shows that the variation of hoop stress is very small at the point with the shield get through and the hoop stress get stable fast.

\section{The V statistic and non-cycle}

Long term memory is an important feature of the fractal structure, and the long-term memory in the nonlinear system is limited,the time dependence on initial value will be reduce when it beyond a certain limit, the system will show the characteristics of independent of each other.Non-cycle stability and time series using V statistics to infer the fractal analysis method,the monitoring points of the circumferential stress time curves of the whole V-log (n) curve,the results as shown in figure $6 \sim 8$.

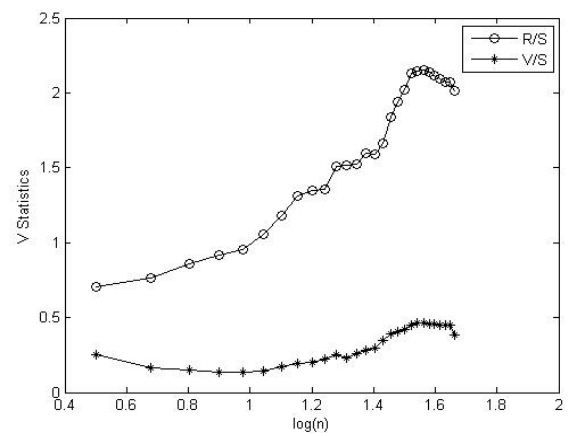

Fig.6 The $\mathrm{V}$ statistic of $\mathrm{R} / \mathrm{S}$ and $\mathrm{V} / \mathrm{S}$ analysis of $+45^{\circ}$ position hoop stress time series

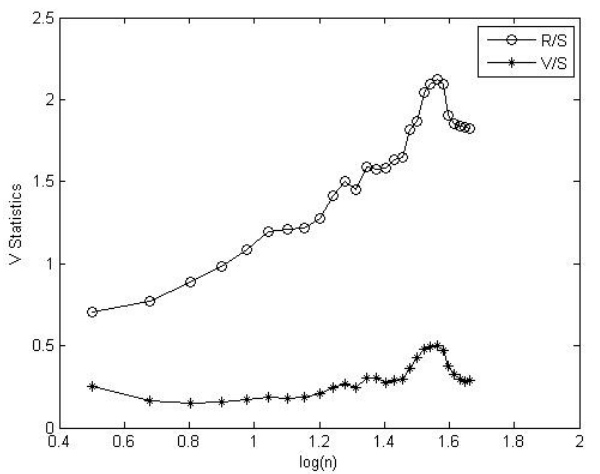

Fig.7 The $\mathrm{V}$ statistic of $\mathrm{R} / \mathrm{S}$ and $\mathrm{V} / \mathrm{S}$ analysis of horizontal position hoop stress time series

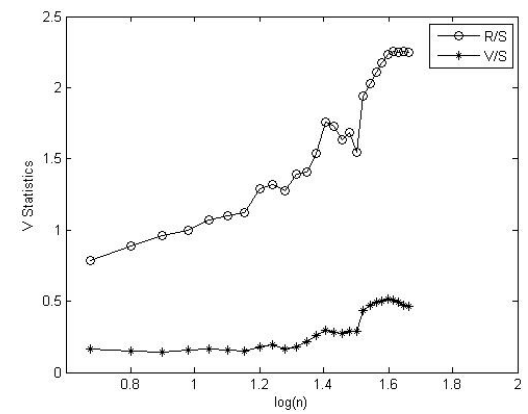

Fig.8 The $\mathrm{V}$ statistic of $\mathrm{R} / \mathrm{S}$ and $\mathrm{V} / \mathrm{S}$ analysis of $-45^{\circ}$ position hoop stress time series

Using $\mathrm{V}$ statistics can determine the effectiveness of $\mathrm{R} / \mathrm{S}$ analysis and $\mathrm{V} / \mathrm{S}$ analysis, when the $\mathrm{H}$ index is greater than 0.5 , the $\mathrm{V}$ statistics curve will be upward sloping. When $\mathrm{H}$ index is 0.5 , the curve will be close to the level. When the index is less than 0.5 , the curve will be downward sloping. The $\mathrm{H}$ index calculated from each monitoring point is greater than 0.5 , the $\mathrm{V}$ statistics curve tend to be upward sloping, this means the $\mathrm{H}$ index calculated by $\mathrm{R} / \mathrm{S}$ analysis and $\mathrm{V} / \mathrm{S}$ analysis is reasonable.

In the +45 degrees position, the $\mathrm{V}$ statistics curve obtained by the $\mathrm{R} / \mathrm{S}$ analysis method exist obvious turning point,by the $\mathrm{V} / \mathrm{S}$ analysis method without obvious turning point, but the 
change rate in the same position of the curve is both zero. In the horizontal position and the -45 degrees position, the statistics curve obtained by R/S analysis method and V/S analysis method are consistent, there are obvious inflection point at the same position. Comprehensively judge the three monitoring points $\mathrm{V}$ statistic curve, when the $\log (\mathrm{n})$ is 1.57 there is an inflection point in $\mathrm{V}$ statistics curve, it can be concluded that the non-cycle of hoop stress time series curves of three monitoring points is 37 days. After thirty-seventh days, the monitoring data affected by the previous data is not obvious, when the $\mathrm{H}$ index is close to 1 , curve change rule will be consistent with before. Hoop stress affected by the shield construction will decrease. Hoop stress will tend to be stable

\section{Conclusion}

There is complex nonlinear characteristic of hoop stress time series curve, we find that it has obvious fractal characteristics by the method of R/S analysis method and V/S analysis method, the variety regulation can be analyzed efficiently by the fractal parameter $\mathrm{H}$ index.

$\mathrm{H}$ index of section $\mathrm{B}$ of three monitoring points are close to one, under the influence of shield construction, the hoop stress variation regularity, while in section $\mathrm{A}$ and section $\mathrm{C}, \mathrm{H}$ index is close to 0.5 , the hoop stress variation has great randomness and the volatility is reflected on curves. The $\mathrm{H}$ index of the overall is greater than 0.5 , the trend will have a lasting characteristic and stable status will not change.

The rationality of two methods in analyzing change rule of hoop stress time series curve have been verified using V statistic, and the non-cycle of each monitoring point is about 37 days, after 37 days, the hoop stress will be more stable and in the case of $\mathrm{H}$ index greater than 0.5 the hoop stress will be in a stable state for a long time.

\section{References}

[1] Jin Xiao-guang,Li Xiao-hong, Gao Peng, et al.Application of Grey Majorzed Model in Tunnel Surrounding Rock Displacement Forecasting[J].Journal of Chongqing University:Natural Science Education, 2002,25(1):1-5.

[2] Zhong Shan. Study on Monitoring Data's Processing and Advance-Alarm/Alarm of Shield Tunnel Engineering[D].Shanghai: Tongji University,2006.

[3] Qiao Zhi-chao,Zhou Jian-chun.Monitoring and Analysis on Surrounding Rock Deformation of Tunnel[J]. Construction Technology,2012,363(41):40-42.

[4] Zhang Meng-xi,Li Gang, Feng Jian-long,et al. Coupling analysis of surrounding rocks in double-arch tunnel by FE and BP neural networks[J].Rock and Soil Mechanics,2008,05:1243-1248.

[5] Hurst H E. long-term storage capacity of reservoirs: An experimental study[J]. Transactions of American Society of civil Engineers, 1951,116:770-808.

[6] Giraitis L,Kokoszka P,Leipus R,et al.Reacaled rariance and related tests for long memory in volatility and levels[J]. Journal of Econometrics,2003,112( 2) : 265-294.

[7] He Ke-qiang,Sun Lin-na,Wang Si-jing.Displacement Fractal Parameter Hurst Index and ITS Application to Prediction of Debris Landslides.[J].Chinese Journal of Rock Mechanics and Engineering, 2009,06:1107-1115. 
[8] JAMES DAVIDSON,NIGAR HASHIMZADE.Type I and Type II Fractional Brownian Motions:A Reconsideration[J].Computational Statistics and Data Analysis,2009(53):2089-2106.

[9] MANDELBROUT B B.The fractal geometry of nature[M]. San Francisco,USA:W. H. Freeman and Company, 1982.

[10] Li Yuan-yao,Yin Kun-long,Cheng Wen-ming.Application of R/S method in forecast of landslide deformation trend[J].Chinese Journal of Geotechnical Engineering,2010,08:1291-1296.

[11] Chen Xue-xi,Song Fu-mei,Yan Zhi-jie.Characteristics of gas emission in coalmine based on fractal dimension theory[J].Journal of Liaoning Technical University ( Natural Science ),2012,05:617-620.

[12] Qiao Mei-ying,Chen Xin,Lan Jian-yi.Study on fractal characteristics of gas emission rate based on V/S analysis[J]. China Coal,2014,10:104-110.

[13] Li Ye-xue,Liu Jian-feng. Study on Deformation Characteristic of Surrounding Rock by R/S Method and Fractal Theory[J]. Journal of Sichuan University (Engineering Science Edition),2010,03:43-48. 